Glover, J. \& Stainer, D. W. (1959). Biochem. J. 72, 79.

Glover, M., Glover, J. \& Morton, R. A. (1952). Biochem. J. $51,1$.

Gray, E. Le B. \& Cawley, J. D. (1942). J. Nutr. 23, 301.

Green, B., Lowe, J. S. \& Morton, R. A. (1955). Biochem. J. 61, 447.

Green, C. (1955). Ph.D. Thesis, University of Liverpool.

Hellman, L., Rosenfeld, R., Gallagher, T. F., Adlersberg, D. \& Wang, C. I. (1953). Circulation, 8, 434.

Hernandez, H. H., Chaikoff, I. L., Dauben, W. G. \& Abraham, S. (1954). J. biol. Chem. 206, 757.

Kenny, A. P. (1952). Biochem. J. 52, 611.

Kodicek, E. \& Ashby, D. R. (1954). Biochem. J. 57, xii.
Macqueen, A. (1948). Ph.D. Thesis, University of Liverpool. Markham, R. (1942). Biochem. J. 36, 790.

Mueller, J. H. (1916). J. biol. Chem. 27, 463.

Page, I. H., Lowis, L. A. \& Plahl, G. (1953). Circulation Res. 1, 87.

Schotz, M. C., Rice, L. I. \& Alfin-Slater, R. B. (1953). J. biol. Chem. 204, 19.

Schwenk, E. \& Werthessen, N. T. (1952). Arch. Biochem. Biophys. 40, 334.

Sobel, A. E. \& Mayer, A. M. (1945). J. biol. Chem. 157, 255.

Spiro, M. J. \& MoKibbin, J. M. (1956). J. biol. Chem. 219, 643.

\title{
Biochemical Aspects of Bovine Ketosis
}

\author{
By S. J. BACH AND K. G. HIBBITT \\ Department of Physiology, University of Bristol
}

\section{(Received 18 August 1958)}

Although studies on ketosis arising from diabetes, starvation and other causes have occupied a host of workers in the past, comparatively little is known of the biochemical aspects of bovine ketosis. Apart from the increased occurrence of ketone bodies in the blood and urine, bovine ketosis is characterized by abnormally low concentrations of blood glucose and liver glycogen (Shaw, 1955). It was decided to analyse the blood of diseased animals for the presence of abnormal quantities of metabolites, such as amino nitrogen, urea, ammonia and (in particular) members of the citric acid cycle. Of the 12 constituents estimated, which included cholesterol, in the serum of approximately seventy normal and diseased animals, the investigation of the levels of pyruvate, citrate, $\alpha$-oxoglutarate and succinate proved the most fruitful. The highly significant abnormalities in the levels of these four components in the serum of ketosed animals represent the main result of this work.

Only one team of workers was found to have reported studies on the levels of pyruvate and $\alpha$-oxoglutarate in the literature. In these Carlström, Myrbäck, Holmin \& Larsson (1939) suggested that in bovine ketosis the blood levels of the two keto acids were above normal, though the opposite view was taken with regard to pyruvate in later work (Carlström, 1944, 1950).

One of the tasks undertaken was the elaboration of specific methods for the estimation of quantities of serum constituents as low as 1-2 $\mu \mathrm{g}$. Another point considered was the decomposition of the blood components during the transport and clotting period in which they were exposed to ambient temperature. This problem has been studied extensively in preceding work (Bach \& Hibbitt,
1958), when storage conditions were found which would ensure the stability of the serum constituents until their estimation was possible.

From the results of the present work it was conconcluded that in bovine ketosis an interference may take place with certain reactions of the Krebs cycle, and further that these disturbances may assist in the explanation of the other biochemical symptoms of the disease. Though no significant differences were found between the serum levels of the nitrogenous components and of cholesterol in normal and ketosed animals, it is thought that the record of results for these constituents in normal and abnormal serum may fill a gap in the literature.

\section{METHODS}

Animals. All the blood samples from normal and ketosed animals were obtained from cows of the Jersey breed. Some of the normal samples were collected from the Veterinary Field Station of the University of Bristol and the remainder of the normal samples as well as all samples from animals suffering from ketosis were collected from Jersey Island.

Collection of samples and analytical methods. The procedure for the collection of blood samples was identical with the one described in previous work (Bach \& Hibbitt, 1958), as were the methods used for the estimation of amino nitrogen, urea, ammonia, ketone bodies, cholesterol and glucose. In view of the findings in the above-mentioned work about the lability of the various serum components, care was taken that these were estimated within that period of time after collection during which the components had previously been found to be stable at ambient temperature (Bach \& Hibbitt, 1958).

Estimation of pyruvate and $\alpha$-oxoglutarate. Hydrazones of these compounds were prepared according to standard methods, the modification described in previous work 
(Bach \& Hibbitt, 1958) being used. The modifications were necessary to avoid the interference of acetoacetic acid in the serum of ketosed animals. The hydrazones were separated by paper chromatography, and were eluted and colorimetrically estimated.

Estimation of citric acid. The pentabromoacetone method was adapted for serum and modifications were elaborated to overcome the interference of ketone bodies and of acid contaminants with the colour reaction (Bach \& Hibbitt, 1958).

\section{Estimation of succinic acid}

A new method was elaborated which was sensitive enough for the estimation of quantities as low as $1 \mu \mathrm{g}$.

Principle. The succinic acid is extracted from deproteinized serum with ether. After evaporation of the ether, the residue is dissolved in phosphate buffer and the enzymic reduction of cytochrome $c$ by succinic acid in the presence and absence of malonate is determined spectrophotometrically.

Procedure. A portion (10 ml.) of serum was deproteinized in a centrifuge tube by adding $50 \mathrm{ml}$. of tungstic acid reagent $[10 \%$ sodium tungstate-water-2/3N-sulphuric acid (1:3:1, by vol.)]. After standing for $10 \mathrm{~min}$. the protein was separated from the supernatant by centrifuging. The succinate was extracted with 20-30 ml. of ether from a known volume (approximately $50 \mathrm{ml}$.) of the supernatant for $16 \mathrm{hr}$. in a Kutscher-Steudel extractor. After the extraction the ether was evaporated under reduced pressure and any traces of moisture in the residue were removed by desiccation in vacuo. The residue was dissolved in $2 \mathrm{ml}$. of $0.3 \mathrm{M}$-phosphate buffer $\left(\mathrm{NaH}_{2} \mathrm{PO}_{4}-\right.$ $\mathrm{NaOH}), \mathrm{pH} 7 \cdot 6$.

To two $1 \mathrm{~cm}$. cells (capacity $4 \mathrm{ml}$.) of a Unicam SP. 500 spectrophotometer were added $0.5 \mathrm{ml}$. of the phosphate buffer, $0.2 \mathrm{ml}$. of sodium cyanide $(0.03 \mathrm{M})$ and $0.5 \mathrm{ml}$. of a well-washed Keilin \& Hartree (1947) succinoxidase preparation in which the final sediment had been suspended in 0.1 M-phosphate buffer ( $\left.\mathrm{NaH}_{2} \mathrm{PO}_{4}-\mathrm{NaOH}\right)$, pH 7.3, containing $0.8 \mathrm{M}$-sucrose. Further additions to both cells were:
$0.5 \mathrm{ml}$. of cytochrome $c(0.214 \mathrm{~mm})$ and $1.1 \mathrm{ml}$. of water. The contents of the cells were gently mixed and a preliminary reading was taken at $550 \mathrm{~m} \mu$. With accurate pipetting and thorough mixing a zero reading can be obtained, though in a few cases this initial reading $\left(R_{1}\right)$ differed slightly from zero, usually by less than $0.001 E$. After the initial reading a portion $(0.4 \mathrm{ml}$.) of the $2 \mathrm{ml}$. of serum extract was added to one cell and an equal volume of water to the other. Readings were taken at 3-5 min. intervals until there was no further reduction of the cytochrome $c$, when the final reading $\left(R_{\Omega}\right)$ was taken. With an active enzyme preparation the readings became constant after 10-30 min.; enzyme preparations taking more than $45 \mathrm{~min}$. were discarded. This procedure was then repeated in the presence of malonate, which was added to both cells in a final concentration of $0.1 \mathrm{M}$ before the initial reading. In this way a second pair of readings $\left(R_{8}\right.$ and $\left.R_{4}\right)$ were obtained. The value $\left(R_{8}-R_{1}\right)-\left(R_{4}-R_{8}\right)$, which ranged from 0.010 to 0.035 , was considered to be the extinction caused through the reduction of cytochrome $c$ by the succinate present in the serum extract. The succinic acid level was calculated from a calibration graph, known amounts of succinate in aqueous solution being used. The same cytochrome $c$ preparation was used for the calibration as was used for the estimation of the serum extract. Recovery experiments for succinate are shown in Table 1. In one set $(A)$ a known amount was added to untreated serum, then extracted from the serum and estimated. In another set $(B)$ the succinate solution was added to the serum extract and then estimated; in a third set $(C)$ aqueous succinate solutions were estimated. It is evident that the losses occurring in set $A$ were mainly due to incomplete extraction of the succinic acid from the serum.

\section{RESULTS}

Glucose and ketone bodies. Table 2 shows the main biochemical characteristics of bovine ketosis, namely a considerable depression of the glucose

Table 1. Recovery experiments with succinate

(A) Serum (10 ml.) containing added amounts of succinate was deproteinized with the tungstic acid reagent (50 ml.) and $50 \mathrm{ml}$. of the protein-free solution was extracted with ether. The residue of the extract was dissolved in 0.3 M-phosphate buffer, $\mathrm{pH} 7.6(2.0 \mathrm{ml}$.), and a sample $(0.4 \mathrm{ml}$.) used for spectrophotometric determination of succinate, as described in Methods. (B) Succinate was added to an ether extract of normal serum. $(C)$ Aqueous solutions of succinate were used instead of the serum extract.

$(A)$

Succinate in $10 \mathrm{ml}$. of serum

$\begin{array}{rcc}\begin{array}{c}\text { Added } \\ (\mu \mathrm{g} .) \\ 0.0\end{array} & \begin{array}{c}\text { Found } \\ (\mu \mathrm{g} .) \\ 6.6\end{array} & \begin{array}{c}\text { Recovery } \\ (\%)\end{array} \\ 6.0 & 10.8 & 70 \\ 12.0 & 14 \cdot 4 & 65 \\ 18.0 & 20.4 & 77 \\ 24.0 & 23.4 & 70 \\ - & - & -\end{array}$

$(B)$

Succinate in $0.4 \mathrm{ml}$
of ether extract

\begin{tabular}{|c|c|c|c|c|}
\hline \multicolumn{3}{|c|}{$\begin{array}{c}(B) \\
\text { Succinate in } 0.4 \mathrm{ml} \\
\text { of ether extract }\end{array}$} & \multicolumn{2}{|c|}{$\begin{array}{c}\begin{array}{c}(C) \\
\text { Succinate in } 0.4 \mathrm{ml} . \\
\text { of water }\end{array} \\
\text {. }\end{array}$} \\
\hline $\begin{array}{c}\text { Added } \\
(\mu \mathrm{gg})\end{array}$ & $\overbrace{\begin{array}{c}\text { Found } \\
(\mu \mathrm{g} .)\end{array}}$ & $\overbrace{\substack{\text { Recovery } \\
(\%)}}$ & $\begin{array}{c}\text { Added } \\
(\mu \mathrm{g} .)\end{array}$ & $\begin{array}{c}E_{550 \mathrm{~m} \mu} \\
\begin{array}{c}\text { (duplicate } \\
\text { experiments) }\end{array}\end{array}$ \\
\hline 0.0 & $1 \cdot 1$ & - & 1.0 & $\begin{array}{l}0.012 \\
0.010\end{array}$ \\
\hline 1.0 & 1.9 & 80 & $2 \cdot 0$ & $\begin{array}{l}0.022 \\
0.023\end{array}$ \\
\hline $2 \cdot 0$ & $2 \cdot 9$ & 90 & $3 \cdot 0$ & $\begin{array}{l}0.036 \\
0.034\end{array}$ \\
\hline 0.0 & 1.2 & - & $4 \cdot 0$ & $\begin{array}{l}0.048 \\
0.049\end{array}$ \\
\hline $\begin{array}{l}3 \cdot 0 \\
4 \cdot 0\end{array}$ & $\begin{array}{l}4.0 \\
4.9\end{array}$ & $\begin{array}{l}93 \\
92\end{array}$ & - & $=$ \\
\hline
\end{tabular}

$(C)$ 
level and a high ketone-body level in the serum of approximately 30 ketosed animals, as compared with the levels of 36 normal ones. The glucose levels of both normal and diseased animals compare well with the findings of other workers where the normal values ranged from 41 to $92 \mathrm{mg}$./ $100 \mathrm{ml}$. (MacDonald, Krueger \& Bogart, 1956) and the ketonaemic values from 15.3 to $42.4 \mathrm{mg}$./ $100 \mathrm{ml}$. (Sampson, Gonzaga \& Hayden, 1933). Total ketone bodies in normal animals amount usually to no more than $11 \mathrm{mg} . / 100 \mathrm{ml}$. (Thin \& Robertson, 1953), as compared with 30-106 mg./ $100 \mathrm{ml}$. in bovine ketosis (Table 2). The bulk of the ketone bodies in diseased animals were found to consist of acetone and $\beta$-hydroxybutyric acid; smaller quantities were present as acetoacetic acid.

It was tempting to investigate whether or not the two pathological phenomena were interconnected. Fig. 1 demonstrates an inverse relationship, so that the severity of the disease can be assessed by either of the two criteria. The position of the line in this figure was calculated as that best fitting the scatter of points. The correlation coefficient was found to be significant at a $5 \%$ level.

Nitrogenous components and cholesterol. As far as can be ascertained from the estimation of concentrations of amino nitrogen, ammonia and urea in the serum of normal and ketosed animals, there appears to be no influence of the pathological condition on the metabolism of protein (Table 3 ). Moreover, except for the normal urea levels, the values obtained showed considerable consistency. not only for the normal but also for the ketosed animals. Though the slight depression of urea nitrogen observed in ketosis as compared with the normal values was not significant, a lower urea level might have been expected in the diseased animals, in view of their reduced food intake. The range of normal urea nitrogen values $(6-22 \mathrm{mg} . /$ $100 \mathrm{ml}$.) was similar to that given by MacDonald et al. $1956(8 \cdot 8-24 \cdot 2 \mathrm{mg} . / 100 \mathrm{ml}$.$) .$

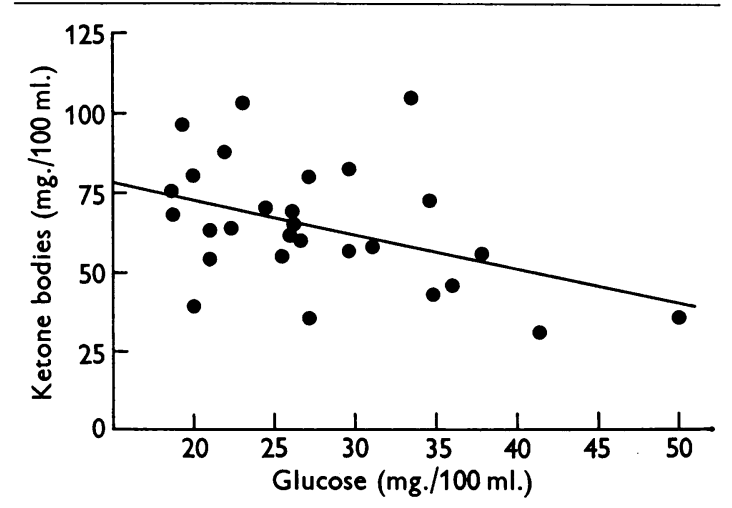

Fig. 1. Interrelation of the serum concentrations of ketone bodies and glucose in bovine ketosis.

Table 2. Glucose and ketone bodies in serum of normal animals and of animals with ketosis

\begin{tabular}{|c|c|c|c|c|}
\hline & \multicolumn{2}{|c|}{ Normal } & \multicolumn{2}{|c|}{ Pathological } \\
\hline & $\begin{array}{c}\text { No. of } \\
\text { cases }\end{array}$ & $\underset{(\mathrm{mg} . / 100 \mathrm{ml} .)}{\text { Mean }}$ & $\begin{array}{c}\text { No. of } \\
\text { cases }\end{array}$ & $\underset{(\mathrm{mg} . / 100 \mathrm{ml} .)}{\text { Mean }}$ \\
\hline Glucose & 36 & $\begin{array}{c}65 \cdot 87 \\
(40 \cdot 0-93 \cdot 0)\end{array}$ & 33 & $\begin{array}{c}28 \cdot 18 \\
(18 \cdot 6-40 \cdot 0)\end{array}$ \\
\hline Acetone & - & 一 & 30 & $\begin{array}{c}34 \cdot 1 \\
(15 \cdot 0-56 \cdot 4)\end{array}$ \\
\hline Acetoacetic acid (as acetone) & - & - & 一 & $\begin{array}{c}6 \cdot 21 \\
(2 \cdot 1-12 \cdot 2)\end{array}$ \\
\hline$\beta$-Hydroxybutyric acid (as acetone) & - & 一 & 29 & $\begin{array}{c}24 \cdot 7 \dagger \\
(12 \cdot 2-43 \cdot 8)\end{array}$ \\
\hline Total ketone bodies (as acetone) & $20^{*}$ & $\begin{array}{c}6 \cdot 1^{*} \\
(2 \cdot 9-10 \cdot 9)\end{array}$ & 29 & $\begin{array}{c}65 \cdot 6 \\
(30 \cdot 6-106 \cdot 0)\end{array}$ \\
\hline
\end{tabular}

* Thin \& Robertson (1953).

t Uncorrected for the presence of propan-2-ol (Thin \& Robertson, 1952).

Table 3. Nitrogenous constituents and 'total' cholesterol in serum of normal animals and of animals with ketosis

\begin{tabular}{|c|c|}
\hline \multicolumn{2}{|c|}{ Normal } \\
\hline $\begin{array}{l}\text { No. of } \\
\text { cases }\end{array}$ & $\begin{array}{l}\text { Mean } \pm \text { s.M.M. } \\
\text { (mg./100 ml.) }\end{array}$ \\
\hline $\begin{array}{l}33 \\
28 \\
35 \\
26\end{array}$ & $\begin{array}{r}5.08 \pm 0.05 \\
0.36 \pm 0.04 \\
13.52 \pm 0.77 \\
205.5 \pm 8.52\end{array}$ \\
\hline
\end{tabular}

\begin{tabular}{|c|c|}
\hline \multicolumn{2}{|c|}{ Pathological } \\
\hline $\begin{array}{l}\text { No. of } \\
\text { cases }\end{array}$ & $\begin{array}{l}\text { Mean } \pm \text { S.r..M. } \\
\text { (mg./100 ml.) }\end{array}$ \\
\hline $\begin{array}{l}14 \\
14 \\
13 \\
14\end{array}$ & $\begin{array}{r}5 \cdot 28 \pm 0.08 \\
0.47 \pm 0.09 \\
11 \cdot 68 \pm 0.70 \\
199.5 \pm 7.43\end{array}$ \\
\hline
\end{tabular}

Amino nitrogen

Ammonia nitrogen

Urea nitrogen

Cholesterol
$13 \cdot 52 \pm 0.77$
$205 \cdot 5 \pm 8 \cdot 52$ 
The ammonia levels in the serum of the normal and ketosed ruminants investigated were slightly higher than those reported in the literature for man. The increase may be due to the predominance of bacterial fermentation in the digestion of ruminants; it could also be argued that a part of the ammonia was formed in the serum during the clotting time by a fluoride-insensitive process.

No influence of the pathological condition was observed on the concentration of amino nitrogen and of cholesterol.

Pyruvate, $\alpha$-oxoglutarate, citrate and succinate. Table 4 shows the serum concentrations of these members of the citric acid cycle in normal and ketosed animals. The differences in these levels between the two groups of animals amounted to several hundred per cent, and are highly significant. Moreover, the individual results showed a surprisingly high degree of consistency in spite of the complexity of the analytical procedure for such small quantities. The pyruvate in ketosed animals was more than $300 \%$ above normal and this phenomenon was paralleled by a strong depression in the amount of citrate. The results for concentrations of $\alpha$-oxoglutarate and succinate were analogous; it was found that in ketosed animals the former was greatly increased and, from the few experiments carried out, that this increase was accompanied by a depression of the level of succinate. Because of the close metabolic relationship between pyruvate and citrate on the one hand and between $\alpha$-oxoglutarate and succinate on the other, an interference with these metabolic reactions in the citric acid cycle was suspected; this will be discussed below. The blood level of pyruvate in normal cows, as estimated by older and less specific methods, was given by Carlström et al. (1939) as 0.4-0.6 mg./100 ml., and that for ketosed animals as $1 \cdot 0-1 \cdot 6 \mathrm{mg} \cdot / 100 \mathrm{ml}$. However, in later work Carlström (1944, 1950) reported that the ketonaemic levels were lower than the normal ones. A blood concentration of $\alpha$-oxoglutarate in bovine ketosis as high as $8 \mathrm{mg} . / 100 \mathrm{ml}$. was claimed by Carlström et al. (1939), though this was estimated by a less specific gravimetric method; Carlström $(1944,1950)$ also stated that the levels of citrate in the diseased animals were generally below normal.
Attempts to correlate the degree of abnormality in the concentrations of the four members of the citric acid cycle with the degree of severity of the disease, as assessed by the abnormal levels of ketone bodies and of glucose, were unsuccessful.

\section{DISCUSSION}

Inasmuch as the amounts of metabolites in the blood can reflect the nature of tissue metabolism, the results of the present investigations may throw some light on the biochemical aspects of bovine ketosis.

The accumulation of pyruvate and the corresponding depression of citrate in the serum of ketosed animals could be interpreted as an interference with the conversion of pyruvate into citrate via acetyl-coenzyme $A$. This phenomenon was paralleled by an accumulation of $\alpha$-oxoglutarate and a depression of succinate, signifying a possible inhibition of the conversion of the former compound into the latter. Since the mechanism of these reactions is very similar and since the reactions require identical cofactors, there is reason to believe than an interference with the latter may be at the root of the disturbance in the Krebs cycle. Two factors which participate in the two reactions are of particular interest: coenzyme $A$ and thiamine pyrophosphate. The fact that $B_{1}$ avitaminosis interferes with the oxidative utilization of pyruvic acid may have been the basis for the therapeutic experiments of Carlström (1950) and of Shaw (1946); neither, however, could find any beneficial effect from administration of the vitamin to animals suffering from bovine acetonaemia.

More evidence is available for the view that a deficiency in coenzyme $\mathbf{A}$ may be partly responsible for the observed abnormal concentrations of members of the Krebs cycle. From the work of Olson \& Kaplan (1948), it was shown that a greatly reduced turnover of pyruvate in liver slices could be obtained from animals deficient in pantothenic acid and in coenzyme A. More support for the above view was obtained through the work of Peeters, Oyaert, Bouckaert \& Haeck (1958), who reported that the acetylating capacity in ketosed animals was lowered as compared with normal

Table 4. Tricarboxylic acid-cycle intermediates in serum of normal animals and of animals with ketosis

\begin{tabular}{|c|c|c|c|c|c|}
\hline \multirow[b]{3}{*}{$\begin{array}{l}\text { Pyruvate } \\
\text { Citrate } \\
\alpha \text {-Oxoglutarate } \\
\text { Succinate }\end{array}$} & \multicolumn{2}{|c|}{ Normal } & \multicolumn{3}{|c|}{ Pathological } \\
\hline & $\begin{array}{l}\text { No. of } \\
\text { cases }\end{array}$ & $\begin{array}{l}\text { Mean } \pm \text { S.R.M. } \\
\text { (mg./100 ml.) }\end{array}$ & $\begin{array}{l}\text { No. of } \\
\text { cases }\end{array}$ & $\begin{array}{l}\text { Mean } \pm \text { S.F.M. } \\
\text { (mg./100 ml.) }\end{array}$ & \% Normal \\
\hline & $\begin{array}{l}28 \\
29 \\
30 \\
14\end{array}$ & $\begin{array}{l}0.55 \pm 0.02 \\
4 \cdot 41 \pm 0 \cdot 09 \\
0 \cdot 19 \pm 0 \cdot 01 \\
0 \cdot 11 \pm 0 \cdot 007\end{array}$ & $\begin{array}{r}\mathbf{3 0} \\
\mathbf{3 3} \\
\mathbf{3 0} \\
\mathbf{5}\end{array}$ & $\begin{array}{ll}1.73 \pm 0.26 & (<0.001)^{*} \\
0.89 \pm 0.06 & (<0.001) \\
0.60 \pm 0.06 & (<0.001) \\
0.06 \pm 0.007 & (<0.01)\end{array}$ & $\begin{array}{r}314 \\
20 \\
316 \\
55\end{array}$ \\
\hline
\end{tabular}

* The figures in parentheses are probabilities calculated by the $t$ test (Fisher, 1938). 
animals. Certain clinical findings also support the view of a coenzyme A deficiency in ketonaemia. The animals are susceptible to the disease exclusively in the post-parturition period, which coincides with that of the highest milk and, in particular, fat production, i.e. when the synthesis of great quantities of butter fat demands excessive amounts of acetyl-coenzyme $A$. In experiments with guinea pigs it has been shown that the amount of coenzyme $A$ in the mammary gland rises steeply in the period of lactation after parturition (Ringler, Baker \& Nelson, 1954), and Read \& Moore (1956) reported that injections of prolactin which induce lactation also increase the coenzyme $\mathbf{A}$ within an hour after injection. It may well be therefore that ketosis occurs as a consequence of the inability of the animal to meet the extra demand for coenzyme A. The demand for the latter is enforced through the fact that the main dietary source of fat in the ruminant is acetate, which has to be activated by coenzyme A for further utilization (Folley \& French, 1950; Balmain, Folley \& Glascock, 1954). According to Kingler et al. (1954), the changes in the concentration of coenzyme $A$ follow the general trend of milk production, and it has been observed by one of us (K.G.H.) that ketosed cattle which maintain milk production at a high level are more resistant to therapy (consisting of intravenous glucose injections) than those in which lactation has rapidly decreased.

A deficiency of coenzyme A could be caused by a lack of adenosine triphosphate, since this is required in several stages in the biosynthesis of the coenzyme (Johnson, 1955). Administration of a mixture of creatine and adenosine triphosphate in conjunction with glucose has been reported to relieve the symptoms of ketosis immediately in many cases (Carlström, 1944, 1950). These observations were confirmed by Olsson (1945), who reported the successful use of an adenosine triphosphate preparation supplemented by glucose and creatine.

A severe hypoglycaemia is one of the striking characteristics of bovine ketosis, and it has been shown in this work that a direct relationship exists between these two symptoms (Fig. 1). The low blood sugar seems to be caused by a disturbance in the mechanism of carbohydrate synthesis which involves adenosine triphosphate, whereas the utilization of glucose remains unaffected (Holmes, 1951). An intereference with the synthetic glucose from pyruvate could thus be a contributing factor to the observed accumulation of pyruvate in the blood of ketosed animals. In agreement with this view, treatment of the disease was in the past mainly confined to attempts to increase the blood sugar by injections of glucose (Shaw, Powell \& White, 1942) and of glucose-forming metabolites such as propionate (Schultz, 1952; Hoflund, Nordström \& Hallgren, 1955), lactate (Seekles, 1951) and glycerol (Johnson, 1954). Administration of such components has met with success after prolonged treatment and it may thus be conceivable that through excessive doses of metabolites, the pace of the Krebs cycle is forced (Krebs, 1957) and the synthesis of adenosine triphosphate and glucose enhanced. Peeters et al. (1958), on the grounds of their acetylating experiments described above, came to strikingly similar conclusions.

\section{SUMMARY}

1. The sera of approximately 70 Jersey cows, half of them suffering from bovine ketosis, were analysed for their content of twelve selected blood constituents. These included four members of the citric acid cycle (pyruvate, citrate, $\alpha$-oxoglutarate and succinate).

2. Known micro-methods were adapted for estimating small amounts of the above compounds and a new method for the estimation of succinic acid was elaborated.

3. A relationship was established between the two principal biochemical characteristics of the disease, i.e. the high concentration of serum ketone bodies and the very low concentration of glucose, so that either phenomenon can be used to assess the severity of the disease.

4. No significant differences between normal and diseased animals were found for aminonitrogen, urea, ammonia and cholesterol.

5. In all pathological cases the pyruvate and $\alpha$-oxoglutarate in serum were several hundred per cent above normal and this was paralleled by a strong depression of the amounts of citrate and of succinate.

6. It was concluded that in bovine ketosis there may exist an interference with the citric acid cycle, notably with those reactions in which pyruvate and $\alpha$-oxoglutarate are converted into citrate and succinate respectively. From the known similarity of the mechanism of the two reactions a deficiency in cofactors common to both was suspected, such as coenzyme $A$ and adenosine triphosphate; the compatibility of such a deficiency with certain symptoms in ketonaemia is discussed.

It is a pleasure to express our gratitude to Mr C. $\mathbf{L}$. Gruchy and Mr G. McCallum, St. Helier, Jersey, as well as to Professor A. Messervy and Mr H. Pearson, University of Bristol, for their valuable help in providing us with blood samples. We also wish to thank Professor D. Keilin, F.R.S., Cambridge University, for advice on the estimation of succinate. We are indebted to the Agrioultural Research Council for financial support for this work and in particular for a personal grant to one of us (K.G.H.). 


\section{REFERENCES}

Bach, S. J. \& Hibbitt, K. G. (1958). Vet. Rec. 70, 473.

Balmain, J. H., Folley, S. J. \& Glascock, R. F. (1954). Biochem. J. 56, 234.

Carlström, B. (1944). Skand. VetTidskr. 34, 222.

Carlström, B. (1950). Vet. Rec. 62, 717.

Carlström, B., Myrbäck, K., Holmin, N. \& Larsson, A. (1939). Acta med. scand. 102, 175.

Fisher, R. A. (1938). Statistical Methods for Research Workers, 7th ed. Edinburgh and London: Oliver and Boyd.

Folley, S. J. \& French, T. H. (1950). Biochem. J. 46, 465.

Hoflund, S., Nordström, G. \& Hallgren, W. (1955). Vet. Bull., Weybridge, 25, 187.

Holmes, J. R. (1951). J. comp. Path. 61, 14.

Johnson, B. C. (1955). Annu. Rev. Bioch. 24, 443.

Johnson, R. B. (1954). Cornell Vet. 44, 6.

Keilin, D. \& Hartree, E. F. (1947). Biochem. J. 41, 500.

Krebs, H. A. (1957). Endeavour, 16, 125.
MacDonald, M. A., Krueger, H. \& Bogart, R. (1956). Tech. Bull. Ore. St. Coll. 36 agric. Exp. Sta. p. 3.

Olson, R. E. \& Kaplan, N. O. (1948). J. biol. Chem. 175, 515.

Olsson, E. (1945). Skand. VetTidskr. 35, 419.

Peeters, G., Oyaert, W., Bouckaert, J. \& Haeck, H. (1958). Zbl. Vet. Med. 5, 43.

Read, M. S. \& Moore, R. O. (1956). Fed. Proc. 15, 535.

Ringler, I., Baker, N. \& Nelson, W. L. (1954). Arch. Biochem. Biophys. 52, 348.

Sampson, S. S., Gonzaga, A. C. \& Hayden, C. E. (1933). Cornell Vet. 23, 184.

Schultz, L. H. (1952). Cornell Vet. 42, 148.

Seekles, L. (1951). Vet. Rec. 63, 494.

Shaw, J. C. (1946). J. Dairy Sci. 29, 131, 151.

Shaw, J. C. (1955). Advanc. vet. Sci. 2, 262.

Shaw, J. C., Powell, R. C. \& White, G. C. (1942). J. Amer. vet. med. Ass. $100,473$.

Thin, C. \& Robertson, A. (1952). Biochem. J. 51, 218.

Thin, C. \& Robertson, A. (1953). J. comp. Path. 63, 184.

\title{
Unsaponifiable Constituents of Liver; Ubiquinone and Substance SG in Various Species
}

\author{
By N. F. CUNNINGHAM AND R. A. MORTON \\ Department of Biochemistry, The University of Liverpool, Liverpool 3
}

(Received 27 August 1958)

The determination of substances present in very small amounts in the unsaponifiable fraction of liver lipids is made difficult by the fact that complete hydrolysis requires the tissue or lipid to be exposed to strong alkali on the boiling-water bath. Substances such as vitamins $\mathrm{K}$ and $\mathrm{E}$ are alkalilabile. and indeed may be destroyed entirely. Cain \& Morton (1955) found that when vitamin A was a relatively plentiful component of the liver, chromatographic and other methods of separation were often vitiated by the presence in the unsaponifiable fraction of vitamin A-decomposition products.

The substance SA of Festenstein, Heaton, Lowe \& Morton (1955) and Cain \& Morton (1955) was also encountered by Lowe, Morton \& Harrison (1953) and by Heaton, Lowe \& Morton (1955, 1957). Because of its widespread occurrence SA has been designated ubiquinone (Morton, Wilson, Lowe \& Leat, 1957).

A second minor constituent of liver unsaponifiable material designated substance SC, was found in very small amounts in normal rat liver (Heaton et al. 1955) and larger amounts of both substance SC and ubiquinone were found in liver from vitamin A-deficient rats.

The main object of the present investigation was to determine whether ubiquinone and substance SC occur in the normal livers of various species.

Festenstein et al. (1955) found ubiquinone to be present in various tissues of pig, horse and rat, including normal rat liver. They showed that it was not a saponification artifact, since the same amount was present in the total lipid as in the unsaponifiable material from the tissue. Saponification of the extracted lipid, however, destroyed it. Thus since it is labile to alkali, ubiquinone is evidently protected in some way during the alkali digestion of the tissue. Ward \& Moore (1955) confirmed the occurrence of an alkali-labile substance with the absorption band at $272 \mathrm{~m} \mu$ of SA in the unsaponifiable material from vitamin A-deficient rat liver. They also observed similar spectra in liver fractions (a) from rats cured of vitamin A deficiency, (b) from sexually immature rats and $(c)$ from normal pigs and normal guinea pigs. Cain \& Morton (1955), in an extensive investigation of horse-liver unsaponifiable matter, found ubiquinone, usually accompanied by cholesta-3:5-dien-7-one. Although both substances show absorption peaks near $270 \mathrm{~m} \mu$, ubiquinone can readily be distinguished from the dienone. The latter is stable in alkaline solution and its spectrum in concentrated sulphuric acid has a characteristic peak at $356 \mathrm{~m} \mu$; ubiquinone- 